\title{
Emotion anticipation induces emotion effects in neutral words during sentence reading: Evidence from event-related potentials
}

\author{
Ling-Chen Chou ${ }^{1} \cdot$ Yan-Lin Pan $^{2} \cdot$ Chia-lin Lee ${ }^{1,3,4,5}$ (D)
}

Accepted: 14 September 2020 / Published online: 13 October 2020

(C) The Psychonomic Society, Inc. 2020

\begin{abstract}
This study examined whether emotion responses during reading are co-constituted by lexical items and the preceding context. Event-related potentials to coherent emotion and neutral words finishing sentences with or without strong constraint for the incoming valence were analyzed. Typical frontal P200 and posterior late positive component (LPC) emotion responses were seen to emotion words relative to neutral words in the neutral context, indicating heightened attention allocation and further valence analysis induced by word-level emotionality. With emotional bias in the context, words elicited reduced N400 responses, indicating facilitated semantic processing. Critically, we obtained evidence for contextualized emotion responses during coherent sentence comprehension. With active anticipation of the incoming emotionality (evidenced by the frontal positivity to plausible emotionally unpredicted words), enhanced P200 and LPC responses were seen to neutral words in emotional contexts. These findings demonstrated that, like word emotionality, emotion-constraining contexts could similarly engage motivational circuits and attention resources, affecting early perception and later further affective evaluation of the incoming information, even for emotionally neutral words. Despite the seeming similarity, multiple routes may be involved for giving rise to these neurophysiological reactions during emotion processing - while lexically driven LPCs were significantly correlated with empathy, contextually driven LPCs were not. Together, these findings provide support for contextualized emotion responses during congruent sentence reading when explicit emotional judgment on the materials is not required. These findings also provide an initial understanding about how these responses are mediated by empathy - an important aspect of human ability to perceive emotion.
\end{abstract}

Keywords Post-N400 frontal positivity $\cdot$ P200 $\cdot$ N400 $\cdot$ LPC $\cdot$ Empathy $\cdot$ Emotion predictive processing

\section{Introduction}

Emotion is highly contextualized. As sensory information gleaned from the stimulus is often ambivalent, emotion perception and emotion experience are thought to be coconstituted by the context (e.g., social situation, body

Chia-lin Lee

chialinlee@ntu.edu.tw

1 Graduate Institute of Linguistics, National Taiwan University, Taipei, Taiwan

2 Graduate Program of Teaching Chinese as a Second Language, National Taiwan University, Taipei, Taiwan

3 Department of Psychology, National Taiwan University, Taipei, Taiwan

4 Graduate Institute of Brain and Mind Sciences, National Taiwan University, Taipei, Taiwan

5 Neurobiology and Cognitive Neuroscience Center, National Taiwan University, Taipei, Taiwan postures, voices, scenes, parallel brain processes) as well as the sensation itself (see Lindquist et al., 2015, for a review). In particular, the constructionist theory of emotion hypothesizes that visual and one's own internal body sensations are made meaningful as instances of different emotions through concept knowledge that is critically anchored by language (Barrett et al., 2007). For example, emotion-ambiguous faces morphed faces depicting an equal blend of happiness and anger, were judged to be happier or angrier when paired with the word "happy" or "angry" (Halberstadt \& Niedenthal, 2001), and individuals primed with conceptual knowledge of fear experienced an unpleasant core affect as evidence that the world was threatening (Lindquist \& Barrett, 2008).

Intriguingly, very little is known about whether emotion perception of a word is similarly influenced by its context in addition to its lexical meaning. Words are conventional symbols that arbitrarily link emotion-related meanings to certain word forms. As associations between word forms and emotions are much less hardwired as emotion and visual or body sensations, it is possible that emotions denoted or connoted by 
words are also malleable and amenable to linguistic context. Studies directly addressing this issue are scarce. Below we reviewed critical prior research leading to the present study.

With neutral or no preceding context, emotionality of individual words has been shown to have a rapid and robust impact on multiple brain responses. For example, relative to emotionally neutral words, emotion words have been shown to elicit enhanced early posterior negativity (EPN) and P200 responses. The EPN occurs 200-300 ms after stimulus onset at temporal-occipital electrodes, similar to the "selection negativity" seen in stimuli with directed attention in scalp distribution and timing, and has been argued to reflect reflex-like attention to the intrinsically relevant emotional features of words (e.g., Kissler et al., 2009; Kotz \& Paulmann, 2011). The EPN is robust and replicable for emotion words presented out of context, but has not been consistently observed with words in sentential contexts (e.g., Bayer, Sommer, \& Schacht, 2010; Holt, Lynn, \& Kuperberg, 2009; Martín-Loeches et al., 2012). Emerging in a similar time range but with an anterior distribution, enhanced anterior P2 to emotion words has been seen with or without sentential contexts, and has also been thought to indicate automatic attention allocation (without context: Kanske \& Kotz, 2007; Wang \& Bastiaansen, 2014; with context: Ding et al., 2015, 2016; also see Kotz \& Paulmann, 2011, for a review). Response differences of N400, a component highly sensitive to meaning processing (Kutas \& Federmeier, 2011), are sometimes observed to differ between emotion and neutral words. However, due to differences in other lexical-semantic factors across studies, the directions of N400 response differences between emotion and neutral words have not been consistent. For example, while less negative N400s were seen to emotion than neutral words in some studies (without context: e.g., Herbert et al., 2008; with context: e.g., Martín-Loeches et al., 2012), more negative N400s were seen to emotion than neutral words in others (with context: e.g., Holt et al., 2009). Finally, emotion words have also been associated with the late positive component (LPC), over central-posterior scalp sites, generally thought to reflect sustained attention and evaluation of the affective stimuli (without context: e.g., Kanske \& Kotz, 2007; with context: e.g., Ding et al., 2015, 2016; Holt et al., 2009; Fields \& Kuperberg, 2012; also see Citron, 2012, for a review).

By contrast, whether and how word-level emotion responses are influenced by emotionally constraining contexts is less well understood. Emotion contextual effects on emotion and neutral words are often examined with different paradigms, making it difficult to compare contextual effects between the two word types. More critically, the majority of this research investigated contextual effects on emotional or linguistic anomalies. Contextual effects observed from anomalies could interact with responses induced by the anomalies per se (e.g., anomaly detection, conflict resolution, reanalysis, repair, etc.), and as a result the contextual effects could be accentuated or omitted because of the anomalies. Thus, it is still an open question whether and how word-level emotion responses are influenced by emotion context in congruent sentences.

Influences of emotion context on emotion words have been studied with the valence-congruency paradigm in which emotion expectation established through preceding context was followed by a word-level valence violation that usually also involves a semantic violation. For example, critical words with emotions opposite to the expected ones were also implausible at the sentence or discourse level in DelaneyBusch and Kuperberg (2013) and León et al. (2010), and were much less expected in meaning than were the critical words with consistent emotions in Moreno and colleagues' work (Moreno \& Rivera, 2014; Moreno \& Vázquez, 2011). Likely due to these mixtures of different violations as well as further complications from a differing amount of emotion constraints across these studies (single-emotion words: Delaney-Busch \& Kuperberg, 2013; paragraph discourse: León, Díaz, de Vega, \& Hernández, 2010; sentence frames: Moreno \& Rivera, 2014, and Moreno \& Vázquez, 2011), very different results have been shown from this line of research. For example, Delaney-Busch and Kuperberg (2013) found that incongruent and congruent emotion words elicit statistically indistinguishable responses, which they interpreted as prioritized emotion processing at the cost of bypassed deep semantic analysis of the valence-incongruous emotion words (Delaney-Busch \& Kuperberg, 2013). However, León et al. (2010) found larger N100 (extending to the P200 time window) and N400 responses to emotionally incongruent emotion words relative to emotionally congruent emotion words, which were considered early detection of semantic violations for inconsistent emotion at the discourse level and consequences due to violations of emotion or semantic expectations. Finally, Moreno and colleagues also found an N400 effect and additionally a late frontal positivity to emotionally incongruent emotion words (Moreno \& Rivera, 2014; Moreno \& Vázquez, 2011), and suggested that the N400 effect may also reflect the lower cloze probability of the unexpected words. They also linked the frontal positivity effect to the predictive language processing literature and interpreted it as a processing cost for encountering a plausible sentence continuation that nevertheless disconfirmed a previously held emotion prediction (Moreno \& Vázquez, 2011; Moreno \& Rivera, 2014).

With regard to neutral words, studies have shown influences from a preceding emotionally charged context on linguistic anomalies carried by neutral words through heightened attention allocation at early perceptual processing and/or later further analysis. For example, Jiménez-Ortega et al. (2012) showed no modulation of emotional context on the N400 semantic anomaly effect, but a modulation of emotional context on the left anterior negativity (LAN) to syntactic anomalies, with neutral words with syntactic errors in the emotional 
context additionally eliciting a greater LAN effect than their counterparts did in the neutral context (also see Espuny et al., 2018, for a similar pattern when arousal was controlled), suggesting a modulation of emotion context on first-pass syntactic processing of neutral words. Ding and colleagues also found that, compared to orthographically valid neutral words, orthographically anomalous neutral words elicited less positive posterior P200s and more negative N400s in the emotionally neutral context, but a larger LPC instead in the emotional context (Ding et al., 2015). These results were taken to suggest compromised early perceptual analysis of neutral words due to the preceding emotional context. In addition, Ding and colleagues found that semantically anomalous neutral words elicited a similar N400 congruity effect but an attenuated P600 effect in an emotional context relative to a neutral context (Ding et al., 2016). These results were interpreted as impaired semantic reanalysis of neutral words following emotional contexts.

To summarize, although the above-reviewed literature demonstrated some influences of emotional context on the processing of embedded words, emotion and neutral words were usually examined using anomalies of different natures. It is difficult to gauge or separate these contextual modulations from the potential influences of effects specifically induced by violations. Therefore, while these findings provide interesting comparisons regarding how emotionality of the context, as opposed to emotionality of the word, may modulate responses to linguistic anomalies (Hinojosa et al., 2019), they do not speak directly to how contextual and lexical emotional features may work in tandem to shape emotion responses to a word. As such, direct and systematic investigations on emotion context modulations on emotion and neutral words using plausible and coherent sentences that are matched for other linguistic features are still needed.

In addition to the lack of direct evidence for whether emotion responses to words are co-constituted by stimuli- and contextual-level emotional features as are emotion responses to non-verbal stimuli, whether emotion perception during reading is mediated by similar factors as in non-verbal domains is also poorly understood. Emotion perception in nonverbal domains, such as perceiving affect from visual stimuli and recognizing one's own and others' emotions, has been shown to be associated with empathy. For example, in response to affective facial stimuli, more empathetic people tend to react more intensively (Dimberg, Andréasson, \& Thunberg, 2011; Sonnby-Borgström, 2002), and elicit higher levels of skin conductance and heart-rate responses (Mehrabian, Young, \& Sato, 1988). Empathy is also found to correlate with people's ability to detect emotion content from colors or even novel abstract graphic designs that do not provide clear emotion information on their own, which requires one to project how these stimuli are likely to be perceived emotionally by others during inter-personal interaction (Mayer et al., 1990).
These results indicate the role of empathy in extracting the emotion content in social contexts. If the human emotional perceptual system is a general system that is not preprogrammed to perceive affect only in non-verbal stimuli, we should expect to see similar associations between empathy and language processing. Empathy has been shown to positively correlate with children's ability to comprehend emotion words (Li \& Yu, 2015), and with people's ability to efficaciously integrate speaker-based information during sentence comprehension to detect conflict with social stereotypes that may have emotion consequences (Van den Brink et al., 2012). However, to our knowledge, no studies have systematically investigated whether empathy also mediates stimuli-level and contextual-level emotion responses to words in sentences. If contextualized emotion perception during reading is mediated by similar factors to non-verbal domains, one would expect to see positive correlations between empathy and lexical-driven and/or context-driven emotion responses assessed during reading.

In light of these considerations, the current study set out to seek direct evidence for joint influences of lexical-level and contextual-level emotion features on word processing during comprehension of congruent and plausible sentences, and to explore whether contextualized emotion responses to verbal stimuli are mediated by similar factors such as empathy to emotion responses to non-verbal stimuli. To these ends, we created emotionally biased sentence frames that were strongly constrained for a specific valence and emotionally unbiased sentence frames that had no such valence constraints; these sentence frames were then continued with emotion or neutral words (Table 1). Sentence frames were matched for general semantic constraints and critical words were matched for semantic expectedness, congruency, plausibility, and other important psycholinguistic features (Table 2). ERP responses were recorded while participants silently read these sentences and judged whether the sentence was coherent and smooth. No explicit emotion evaluation on the materials was required.

We planned to first establish some basic effects. We first validated our constraint manipulation, focusing on the postN400 frontal positivity that has been linked to conceptual and emotion predictive processing of words (Federmeier et al., 2007; Moreno \& Rivera, 2014; Van Petten \& Luka, 2012). If the contexts were emotionally constraining and participants were actively anticipating the emotionality of the upcoming words, we would expect the target words to elicit a larger frontal positivity when emotionally unpredicted (i.e., neutral words in emotional context; emotion words in neutral context) relative to when predicted (i.e. neutral words in neutral context; emotion words in emotional context), despite both cases being coherent and plausible. Having established this, we expect to replicate word-level ERP emotion effects in the neutral context, including enhanced P200 and central-posterior LPC responses to emotion relative to neutral words. As past 
Table 1 Example sentences

Emotionally biased context + Emotion target word

這對銀色情侣公開相擁親吻, 在路上大秀甜蜜。

The celebrity couple hugged and kissed each other in public, showing

their sweetness on the street.

告白不下十次依然被拒絕, 承翰最後只好作罷。

Cheng-Han has proclaimed his love many times but still got refused, in

the end he had no choice but gave up.

Emotionally biased context + Neutral target word

情侣間有問題卻一直沒解決, 時間一久終究會浮現。

There have been long-standing and unresolved issues between the couple, which will eventually surface as time goes by.

宗翰老來得子, 等不及要分享初為人父的心情。

Zōng-hàn got his child at an old age, and he cannot wait to share

this feeling of being a father.

Emotionally unbiased context + Emotion target word

他最近每天忙著趕實驗, 希望能盡快得到實驗成果。

He is busy with experiments recently, hoping to get positive results for his experiments as soon as possible.

對這次意外事件, 相關單位願意扛下所有損失。

For this accident, the relevant departments are willing to bear all losses.

Emotionally unbiased context + Neutral target word

看了電影介紹後, 才發現女主角可以穿越古今。

After watching the movie preview, we found out the female protagonist could travel through time.

對西方觀眾而言, 功夫電影總能吸引他們的注意。

To western audiences, kung-fu movies can always attract their attention.

Final critical sentence words are underlined. English translations are given below each Chinese example sentence

findings on the N400 emotion effects have been mixed, we do not have specific predictions regarding the direction of this effect between emotion and neutral words.

Of central interest to this study, we would then examine whether emotion responses to words are co-constituted by the word itself as well as the context by analyzing P200, N400, and LPC responses in the emotional sentences. If emotion responses to words are solely driven by their lexical meanings and are not affected by the context, identical response patterns to emotion and neutral words across emotional and neutral contexts would be expected. However, if emotion responses to words are contextualized as they are for non-verbal sensations, we expect to see different response patterns between the emotional and neutral contexts. Based on findings from non-verbal materials showing enhanced responses to emotion stimuli apprehended under emotion expectation (Gole et al., 2012; Lin et al., 2012), we would expect to see emotion effects in emotional contexts that are qualitatively similar to those seen in neutral context but greater in magnitude. Alternatively, based on findings showing that emotion expectation could trigger the attention and evaluative system for subsequent words (e.g., Hinojosa et al., 2012), we would expect to see similar increases in attention and evaluative responses regardless of the valence of the incoming word. Finally, we explored whether stimulus-driven and/or context-driven emotion responses to a word could be explained by an individual's empathy ability, similarly to what was observed with emotion responses to non-verbal stimuli.

\section{Method}

\section{Stimuli}

Two factors of contextual bias in the sentence frames (emotionally biased vs. unbiased) and target word type (emotion vs. neutral) were fully crossed. Table 1 provides the examples. Emotional bias of a sentence frame was quantified using the operational index - valence constraint. Each sentence up till the last word was first submitted for a cloze test where participants were asked to complete the sentence frame with the first word they had in mind, a task that has been widely used for quantifying semantic expectancy (Taylor, 1953). After the cloze test, a different group of participants rated the valence and arousal of all the completions elicited in the cloze test. For all variables, each item was rated by 20 individuals who did not participate in the ERP experiment. Valence constraint for each sentence was then computed as a weighted average of the valence values of all completions elicited for that sentence, taking into account each completion's cloze probability. Based on the results of these ratings, a final set of emotionally biased and unbiased sentence stimuli were selected (referred to as "emotional" and "neutral" in brief henceforth). For emotional sentences, equal numbers of sentence frames were selected to bias toward positive and negative valences. Experimental sentences were mixed with implausible fillers for a coherent judgment task. Implausible sentences were created by swapping the sentence final words among sentences in the same condition. This arrangement prevented participants from being able to anticipate implausible endings, thereby encouraging them to pay close attention to all sentences. These sentences were arranged into two lists, such that each sentence frame and target word was seen by each participant only once.

Plausibility differed significantly between plausible and implausible sentences $(p<0.0001)$, but was matched among plausible sentences across contexts (emotion and neutral), types of word valence (positive, neutral, and negative), and lists (list 1 and 2) ( $p s>0.2)$. Among the plausible experimental sentences, sentence frames differed significantly in their valence constraint between emotional and neutral contexts $(p$ $<0.0001$ ), but were matched for semantic constraint (indexed by the highest cloze probability for each sentence frame) across contexts, word valence, and lists $(p s>0.1)$. Sentence final target words differed significantly on valence and arousal 
Table 2 Mean values (with standard deviations in parentheses) of lexical and sentential features of the stimuli in each condition

\begin{tabular}{|c|c|c|c|c|c|c|c|c|}
\hline \multicolumn{3}{|l|}{ Context } & \multicolumn{3}{|c|}{$\begin{array}{l}\text { Emotionally biased } \\
\text { (High valence constraint) }\end{array}$} & \multicolumn{3}{|c|}{$\begin{array}{l}\text { Emotionally unbiased } \\
\text { (Low valence constraint) }\end{array}$} \\
\hline \multicolumn{3}{|l|}{ Target words } & Positive & Negative & Neutral & Positive & Negative & Neutral \\
\hline \multicolumn{3}{|c|}{ Number of trials in each list } & 13 & 13 & 26 & 13 & 13 & 26 \\
\hline \multirow[t]{3}{*}{$\begin{array}{l}\text { Sentence } \\
\text { frame }\end{array}$} & \multirow[t]{2}{*}{$\begin{array}{l}\text { Valence } \\
\text { constraint }\end{array}$} & $\begin{array}{l}\text { Raw score } \\
{[1: \text { most negative; } 9 \text { : most positive }]}\end{array}$ & $6.8(0.4)$ & $2.6(0.4)$ & $4.9(2.0)$ & $5.4(0.4)$ & $5.0(0.5)$ & $5.3(0.6)$ \\
\hline & & $\begin{array}{l}\text { Deviance from neutral } \\
\text { [|Rated score - 5|; possible range } \\
0-4]\end{array}$ & $1.8(0.4)$ & $2.4(0.4)$ & $1.9(0.4)$ & $0.5(0.3)$ & $0.4(0.3)$ & $0.5(0.4)$ \\
\hline & \multicolumn{2}{|c|}{ Semantic constraint $(\%)$} & $62 \%(25 \%)$ & $66 \%(19 \%)$ & $58 \%(20 \%)$ & $67 \%(24 \%)$ & $55 \%(22 \%)$ & $61 \%(24 \%)$ \\
\hline \multirow[t]{9}{*}{ Critical word } & \multirow[t]{2}{*}{ Valence } & $\begin{array}{l}\text { Raw score } \\
{[1: \text { most negative; } 9 \text { : most positive }]}\end{array}$ & $7.1(0.4)$ & $2.4(0.5)$ & $5.0(0.6)$ & $6.9(0.5)$ & $2.7(0.5)$ & $5.1(0.5)$ \\
\hline & & $\begin{array}{l}\text { Deviance from neutral } \\
\text { [|Rated score - 5|; possible range } \\
0-4]\end{array}$ & $2.1(0.4)$ & $2.6(0.5)$ & $0.5(0.3)$ & $1.9(0.5)$ & $2.3(0.5)$ & $0.4(0.3)$ \\
\hline & \multicolumn{2}{|c|}{$\begin{array}{l}\text { Arousal } \\
{[1: \text { least arousing; } 9: \text { most arousing }]}\end{array}$} & $5.2(0.8)$ & $5.4(0.9)$ & $3.8(1.2)$ & $4.8(0.9)$ & $4.8(1.0)$ & $3.1(0.9)$ \\
\hline & \multicolumn{2}{|c|}{ Cloze probability $(\%)$} & $5 \%(4 \%)$ & $4 \%(5 \%)$ & $4 \%(7 \%)$ & $3 \%(5 \%)$ & $4 \%(6 \%)$ & $6 \%(5 \%)$ \\
\hline & \multicolumn{2}{|c|}{$\begin{array}{l}\text { Plausibility } \\
\text { [1: least plausible; } 7 \text { : most plausible }]\end{array}$} & $6.1(0.7)$ & $5.4(0.8)$ & $5.0(1.1)$ & $5.9(0.6)$ & $5.4(0.7)$ & $6.0(0.8)$ \\
\hline & \multicolumn{2}{|c|}{$\begin{array}{l}\text { Familiarity } \\
\text { [1: least familiar; } 7 \text { : most familiar] }\end{array}$} & $6.1(0.5)$ & $6.0(0.5)$ & $6.3(0.4)$ & $6.3(0.4)$ & $6.1(0.5)$ & $6.1(0.5)$ \\
\hline & \multicolumn{2}{|c|}{$\begin{array}{l}\text { Concreteness } \\
{[1: \text { least concrete; } 7 \text { : most concrete] }}\end{array}$} & $4.1(1.2)$ & $3.8(1.0)$ & $3.7(1.0)$ & $4.2(1.1)$ & $4.4(0.9)$ & $4.1(1.2)$ \\
\hline & \multicolumn{2}{|c|}{ Word length } & $2.1(0.3)$ & $2.0(0.3)$ & $2.0(0.2)$ & $2.0(0.2)$ & $2.0(0.2)$ & $2.0(0.3)$ \\
\hline & \multicolumn{2}{|c|}{ Number of strokes } & $24.5(7.3)$ & $22.0(6.1)$ & $21.0(7.5)$ & $25.2(7.4)$ & $23.1(5.0)$ & $20.5(6.3)$ \\
\hline
\end{tabular}

values across word valence $(p s<0.0001)$, but were matched for familiarity, cloze probability, concreteness, word length, and number of strokes across contexts, word valence, and lists ( $p$ s $>0.1$ ). These properties are summarized in Table 2 .

Each participant was randomly assigned to one list and read 208 sentences in the ERP experiment, with 104 experimental sentences (26 emotion words - 13 positive and 13 negative, and 26 neutral words for each context type) and 104 implausible filler sentences.

\section{Participants}

Twenty-seven young adults from Taipei, Taiwan participated in this study; seven were excluded in the analysis due to excessive artifacts (remaining participants: 11 males; mean age 22.8 years, range 21-27). All were native speakers of Mandarin Chinese with no consistent exposure to other languages other than Taiwanese before 5 years of age (assessed by language questionnaires including the Chinese versions of exposure to print test; Stanovich \& West, 1989). All were right-handed as assessed by the Edinburgh Inventory (Oldfield, 1971), had normal or corrected-to-normal vision, and no history of neurological or psychiatric disorders, brain damage, or depression (assessed by the Taiwanese Depression
Questionnaire; Lee et al., 2000). All participants provided signed written informed consent prior to the study; all protocols were approved by the Institutional Review Board at the National Taiwan University.

\section{Experimental procedure}

Participants were seated $100 \mathrm{~cm}$ in front of a computer monitor in a quiet shielded room. Before the experiment, participants were given instructions and a 20-trial practice to familiarize with the task and the experimental environment. Each trial began with a display of a fixation cross in the center of the screen for $500 \mathrm{~ms}$. After an inter-stimulus interval (ISI) of 500 ms, a sentence was presented word by word in the center of the screen. Each word was presented for $200 \mathrm{~ms}$, followed by a 150-ms blank screen. The sentence final target word was followed by a blank screen of 1,300 $\mathrm{ms}$ and then a question mark. To encourage participants to pay close attention to the sentences, participants were instructed to judge whether the sentence was coherent and smooth ('tōng shùn ma?') by pressing either a "yes" or a "no" button on two number pads held in each hand. The question disappeared upon the buttonpressing response and the next trial began after $1.5 \mathrm{~s}$. After the ERP task, participants completed the Chinese version of the 
Questionnaire Measure of Emotional Empathy (Chan, 1986; Mehrabian \& Epstein, 1972).

\section{ERP recording and data analysis}

The electroencephalogram (EEG) was recorded from 33 sintered $\mathrm{Ag} / \mathrm{AgCl}$ electrodes arranged according to the 10 20 system (QuikCap, Neuromedical Supplies, Sterling, TX, USA). All scalp electrodes were referenced on-line to a common vertex reference located between $\mathrm{Cz}$ and $\mathrm{CPz}$, and rereferenced off-line to the average of the right and left mastoids. Vertical eye movements were recorded by a pair of electrodes placed on the supraorbital and infraorbital ridges of the left eye, and horizontal eye movements were recorded by a pair of electrodes placed lateral to the outer canthus of both eyes. Electrode impedance was kept below $5 \mathrm{k} \Omega$ for all electrode sites. The continuous EEG was amplified with the SYNAMPS2 amplifiers (Neuroscan, Inc., EL Paso, TX, USA) through a band-pass filter of $0.05-100 \mathrm{HZ}$ and digitized at a sampling rate of $1,000 \mathrm{~Hz}$.

Offline data analysis was done using the EEGLAB (Delorme \& Makeig, 2004) and ERPLAB (Lopez-Calderon \& Luck, 2014) toolboxes for MATLAB (Natick, MA, USA). Epochs of EEG data were taken from $100 \mathrm{~ms}$ before stimulus onset to 1,000 ms after. Artifacts were identified first using algorithms in ERPLAB, including moving window peak-topeak and step functions applied to eye channels to identify blinks and horizontal eye movements, and a simple voltage threshold function applied to all scalp channels to identify epochs with amplitudes exceeding $\pm 100 \mu \mathrm{V}$. A second-pass manual artifact detection that was blind to the identity of the condition and the participant was then done to ensure that all artifacts were sufficiently identified. Trials contaminated by artifacts from amplifier blocking, signal drifting, eye movements, or muscle activity were rejected off-line before averaging. Trial loss averaged $16.27 \%$ (mean and range of the numbers of epochs averaged for each condition were 22 (18-26), 22 (17-26), 22 (18-26), and 22 (18-26) for emotion and neutral words in emotional and neutral contexts, respectively). Artifact-free ERPs were then averaged by stimuli type after subtraction of the 100-ms pre-stimulus baseline. Prior to statistical analyses, ERPs were digitally filtered with a low pass of $30 \mathrm{~Hz}$. Time windows and electrodes chosen for statistical analysis were determined based on the effort to reduce spatial and temporal overlap among effects within the limit of conventional measures for these ERP components in the literature (e.g., Frontal positivity: Moreno \& Rivera, 2014; Moreno \& Vázquez, 2011; Ryskin et al. 2020; P200: Kanske \& Kotz, 2007; Wang \& Bastiaansen, 2014; N400: Ding et al., 2015, 2016; Kutas \& Federmeier, 2011; LPC: Holt et al., 2009; Fields \& Kuperberg, 2012). To correct for violations of sphericity associated with repeated measures, the Greenhouse-Geisser adjustment to the degrees of freedom was applied for each analysis of variance (ANOVA). Consequently, for all $\mathrm{F}$ tests with more than one degree of freedom in the numerator, the corrected $\mathrm{P}$ value is reported. In addition, significance levels of all pairwise comparisons and correlational analyses were adjusted for multiple comparisons using the false discovery rate (FDR) method, and Benjamini-Hochberg adjusted $\mathrm{P}$ values were reported.

\section{Results}

\section{Behavioral}

As expected, plausible sentences were considered much more coherent and smooth than were implausible sentences (plausible sentences: $\mathrm{M}=0.76$; $\mathrm{SD}=0.1$; implausible sentences: $\mathrm{M}=0.01$; $\mathrm{SD}=0.01)[\mathrm{t}(19)=32.18, \mathrm{p}<.00001]$, indicating that participants were engaged and attentive to the stimuli during the experiment. Considering that judgments about whether a sentence is smooth or coherent may also be affected by (un)predicted choice of word, we further analyzed the endorsement rates as a function of word emotionality and expectancy. The results showed significant effects of Expectancy $\left[F(1,19)=105.09, p<.001, \eta^{2}{ }_{G}=\right.$ 0.35], Emotion $\left[F(1,19)=29.52, p<.001, \eta_{G}^{2}=0.06\right]$, and an interaction between the two $\left[\mathrm{F}(1,19)=35.85, \mathrm{p}<.001, \eta^{2}{ }_{\mathrm{G}}=\right.$ 0.12]. Further pairwise comparisons showed that for both emotion and neutral words, words fitting the emotion prediction of the sentence context were more likely to be endorsed as smooth and coherent than words that did not fulfill the emotion prediction (emotion words: $\mathrm{t}(19)=3.59, \mathrm{p}<0.005, \mathrm{~d}=0.8$; neutral words: $\mathrm{t}(19)=12.73, \mathrm{p}<0.001, \mathrm{~d}=2.85)$.

\section{ERP results}

The grand-average ERP waveforms to sentence-final words in each of the four plausible experimental conditions are shown in Fig. 1 for emotion predictability effects and Fig. 2 for contextualized emotion effects at a representative sample of electrodes. As shown in Fig. 1, emotionally unpredicted emotion and neutral words elicited a post-N400 frontal positivity over anterior regions. In addition, emotion words appeared to elicit less negative N400 responses when they were emotionally predicted than unpredicted despite being plausible and coherent in both cases. Figure 2 shows the responses to emotion and neutral words as a function of emotional constraint in the context. Similar to what was reported in prior research, emotion words elicited enhanced anterior P200 responses and a posterior LPC relative to neutral words in the neutral context. In addition, some notable contextual modulations can be seen with a boost of P200 and LPC responses to the neutral words in the contextually biased context. 


\section{All words}
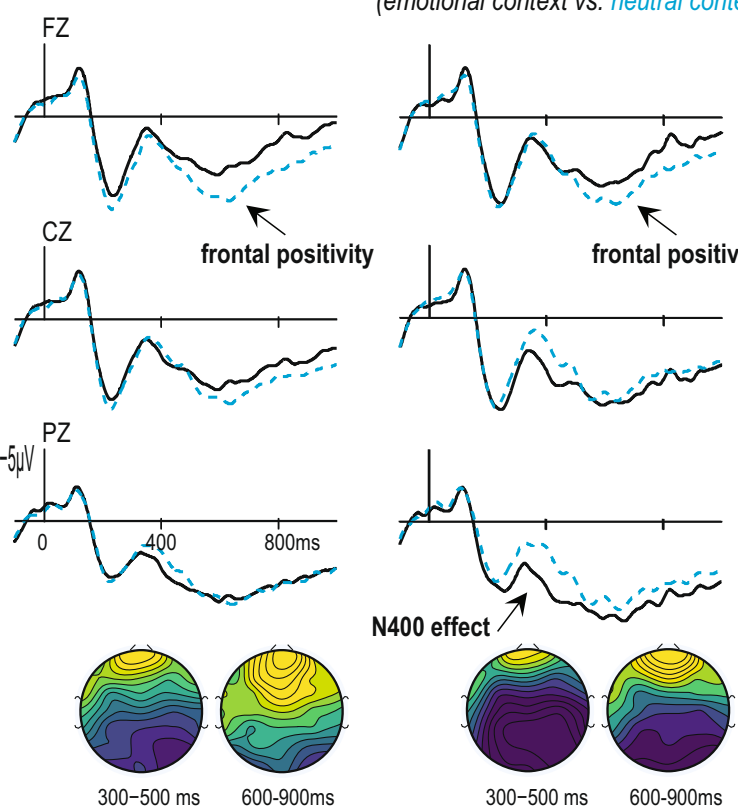

Fig. 1 Grand average event-related potentials (ERPs) at three representative electrode sites are plotted for all words (left column), emotion words (middle column), and neutral words (right column) when they were emotionally unexpected (blue dashed line) versus emotionally

\section{Manipulation check: Emotion predictability effects}

Frontal positivity (600-900 ms) We examined the post-N400 frontal positivity responses for both emotion and neutral words when they were emotionally unpredicted (emotion words in neutral context and neutral words in emotional context) versus when they were predicted (emotion words in emotional context and neutral words in neutral context). Mean amplitudes were submitted for analyses of variance (ANOVAs) for responses recorded over frontal channels (FP1, FPZ, FP2, F3, FZ, and F4), with within-subjects factors of Emotion Expectancy (emotionally predicted vs. emotionally unpredicted) and Emotionality of the target words (emotional vs. neutral). There was a significant main effect of Emotion Expectancy $\left[F(1,19)=18.58, \mathrm{p}<0.001, \eta_{\mathrm{G}}^{2}\right.$ $=.05]$, but no effects of Emotion $\left[\mathrm{F}(1,19)=0.64, \mathrm{p}=.44, \eta_{\mathrm{G}}{ }_{\mathrm{G}}\right.$ $=.001]$ nor interaction between the two $[\mathrm{F}(1,19)=0.02, \mathrm{p}=.90$, $\left.\eta_{\mathrm{G}}^{2}<.001\right]$. Confirmatory pairwise comparisons showed that Emotion Expectancy effects were statistically significant for both emotion [t(19) $=3.01, \mathrm{p}=0.01, \mathrm{~d}=0.67]$ and neutral words $[t(19)=2.59, p=0.02, d=0.58]$.

N400 (300-500 ms) As predictability manipulations sometimes also lead to changes in the N400 component (e.g., Federmeier et al., 2007), we also ran an ANOVA with the same factors on the mean amplitudes of N400 responses recorded over central-posterior channels $(\mathrm{CP} 3, \mathrm{CPZ}, \mathrm{CP} 4, \mathrm{P} 3$, $\mathrm{PZ}$, and $\mathrm{P} 4)$. The results showed no significant effects of
Neutral words

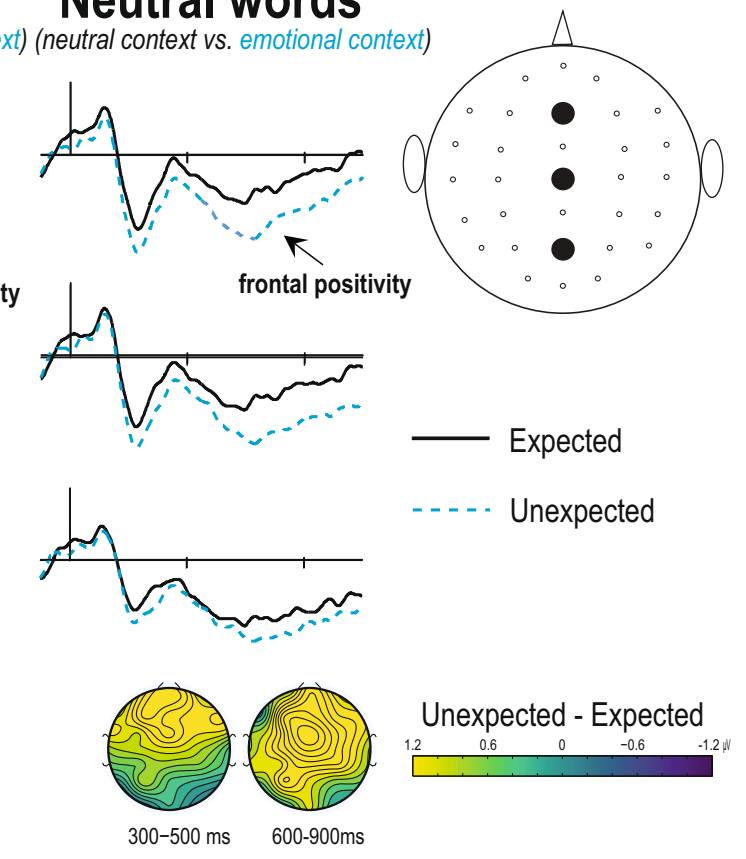

expected (black solid line). Positions of the plotted sites are indicated by filled circles on the head diagram (nose at top). For this and all following figures, negative is plotted up; waveforms were filtered with a low pass at $20 \mathrm{~Hz}$ for illustration purposes

Expectancy $\left[\mathrm{F}(1,19)=2.8, \mathrm{p}=0.11, \eta_{\mathrm{G}}^{2}=0.02\right]$ or Emotion $\left[F(1,19)=3.1, p=0.09, \eta_{G}^{2}=0.03\right]$. However, there was a significant interaction $\left[\mathrm{F}(1,19)=13.71, \mathrm{p}<0.005, \eta_{\mathrm{G}}^{2}=\right.$ $0.07]$. Subsequent pair-wise comparisons showed a significant N400 reduction for expected relative to unexpected emotion words $[t(19)=4.24, p=0.001, d=0.95]$, but no significant difference for neutral words $[\mathrm{t}(19)=1.12, \mathrm{p}=0.28, \mathrm{~d}=0.25]$.

\section{Word-level and contextual-level emotion effects}

Having validated the manipulation on emotion constraint in the context, we next examined the P200, N400, and LPC emotion effects as a function of word-level and contextuallevel emotionality. Analyses were conducted on mean amplitudes of data measured between 150 and $300 \mathrm{~ms}$ after stimulus onset over frontal electrodes (FP1, FPZ, FP2, F3, FZ, F4, FC3, FCZ, FC4) for the P200 effects, and between $300-500 \mathrm{~ms}$ and 600-900 ms over central-posterior electrodes (CP3, CPZ, CP4, P3, PZ, and P4) for the N400 and LPC effects, respectively. These measures were submitted to separate ANOVAs, each with within-subjects factors of Word Emotionality (emotional vs. neutral) and Valence Constraint of the sentence frames (high vs. low).

P200 (150-300 ms) The main effects of Word Emotionality and Valence Constraint were not significant [Word Emotionality: $\mathrm{F}(1,19)=0.48, \mathrm{p}=.50, \eta^{2}{ }_{\mathrm{G}}=.00$; Valence 

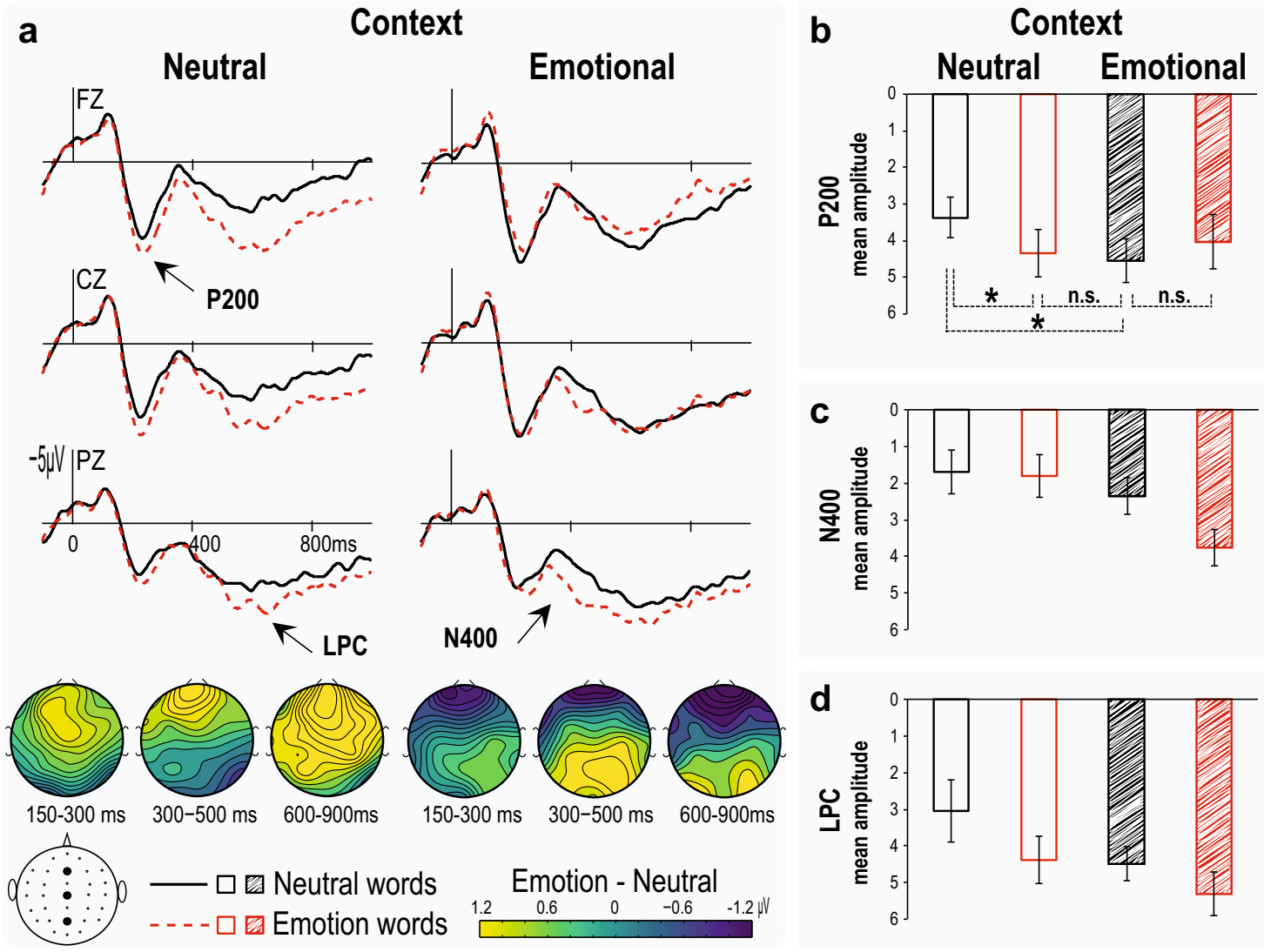

Fig. 2 (A) Grand average event-related potentials (ERPs) at three representative electrode sites are plotted for emotion words (red dashed line) and neutral words (black solid line) in emotionally unbiased neutral context (left column) and emotionally biased emotional context (right

column). Bar graphs show the mean amplitudes of the components of interest - P200 (B), N400 (C), and LPC (C) - measured over time windows and electrodes used for statistical analysis. Results of pairwise comparisons for P200 are indicated in the graph. ${ }^{*} \mathrm{p}<.05$; n.s. not significant

Constraint: $\left.F(1,19)=1.66, p=.21, \eta_{G}^{2}=.01\right]$. However, there was a significant interaction between Word Emotionality and Valence Constraint $\left[\mathrm{F}(1,19)=11.02, \mathrm{p}<0.005, \eta_{\mathrm{G}}^{2}=.02\right]$. Subsequent pair-wise analyses showed a significant Emotion effect in neutral sentences (low valence constraint), with enhanced P200 responses to emotion words relative to neutral words $[t(19)=2.96, p<0.05, d=0.66]$. However, there was no significant Emotion effect in emotional sentences (highvalence constraint) $[t(19)=1.08, p=0.39, d=0.24]$. This $a b-$ sence of the Emotion effect was driven by neutral words in emotional sentences showing enhanced P200 responses that were statistically equivalent with the P200s to emotion words in neutral sentences $[t(19)=0.66, p=0.52, d=0.15]$ and are likewise larger than P200s to neutral words in neutral sentences $[\mathrm{t}(19)=2.81, \mathrm{p}<0.05, \mathrm{~d}=0.63]$ (Fig. 2B).

N400 (300-500 ms) There was no effect of Emotion $[F(1,19)=$ $\left.3.1, p=0.09, \eta^{2}{ }_{G}=0.03\right]$ or Emotion by Constraint interaction $\left[F(1,19)=2.8, p=0.11, \eta^{2}{ }_{G}=0.02\right]$ However, there was a significant effect of Valence Constraint $[F(1,19)=13.71$, $p<$ $\left.0.005, \eta^{2}{ }_{G}=0.07\right]$, with reduced $\mathrm{N} 400$ responses for words in a high- than a low-constraint context. Mean amplitudes for words were less negative (more positive) when preceded by a high-valence constraint context $(3.05 \mu \mathrm{V})$ than a low-valence constraint context $(1.75 \mu \mathrm{V}$ ) (Fig. 2C).

LPC (600-900 ms) There was a significant main effect of Word Emotionality $\left[\mathrm{F}(1,19)=12.38, \mathrm{p}<0.005, \eta_{\mathrm{G}}^{2}=0.035\right]$, with larger LPC responses for emotion words than neutral words (mean amplitudes for emotion words and neutral words are $4.85 \mu \mathrm{V}$ and $3.76 \mu \mathrm{V}$, respectively). There was also a significant main effect of Valence Constraint $[F(1,19)=6.78$, $p<$ $\left.0.05, \eta_{\mathrm{G}}^{2}=0.04\right]$, with larger LPCs to words in a highconstraint context than in a low-constraint context [mean amplitudes for words in high- and low-constraint sentences were $4.90 \mu \mathrm{V}$ and $3.72 \mu \mathrm{V}$, respectively]. Despite a similar trend of larger response boost in neutral words in the emotional context as was seen for the P200 component, word emotionalty and valence constraint did not interact for the LPC responses $\left[F(1,19)=0.35, p=0.56, \eta^{2}{ }_{G}=0.00\right]$, possibly due to the small sample size (Fig. 2D). 


\section{Correlational analysis between empathy and emotional responses}

Following the results reported in the previous section, we then examined whether stimulus-driven and/or context-driven emotion responses can be accounted for by an individual's emotional empathy scores. The mean empathy score of the group was 37.45 (range 4-78; mean for female: 31.2; mean for male: 42.5). Participant's empathy scores were regressed against lexical-driven emotion responses - P200 and LPC responses to emotion words in neutral sentences, and context-driven emotion responses - P200 and LPC responses to neutral words in emotional sentences, and LPC responses to emotion words in emotional sentences. Results showed that empathy scores reliably correlated with the LPC responses to emotion words in the neutral context $(r=0.55, p=0.03)$ ] (Fig. $3 \mathrm{~A})$. However, no significant results were obtained for correlations with other emotion effects (P200s to emotion words in neutral context: $\mathrm{r}=0.1, \mathrm{p}=0.34 ; \mathrm{P} 200$ and LPC responses to neutral words in emotional context: $\mathrm{r}=0.26, \mathrm{p}=0.34 ; \mathrm{r}=$ $0.22, \mathrm{p}=0.29$; LPC responses to emotion words in emotional context: $\mathrm{r}=0.18, \mathrm{p}=0.29$ ).

To illustrate the correlation between the LPC responses and emotional empathy, we applied a median split of the participants based on their empathy scores. Figure $3 \mathrm{~B}$ shows that relative to neutral words in the neutral context (dashed line), larger LPCs to emotion words in the neural context (orange) can be seen to the higher empathy group, while both groups elicited similarly enhanced LPCs to emotion words in the emotional context (dash-dotted line).

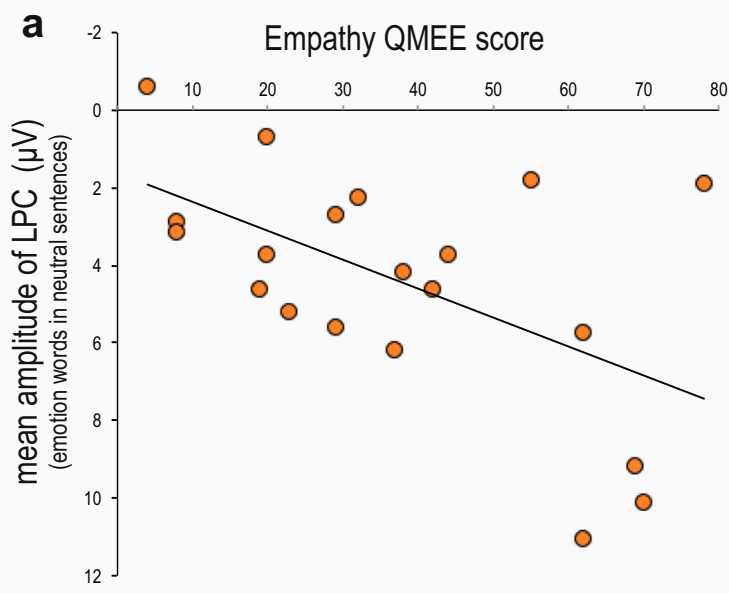

Fig. 3 (A) The scatter diagram shows a correlation between emotional empathy scores (QMEE) and the mean amplitudes of LPC responses to emotion words in neutral sentences, with higher scores associated with larger LPC responses. (B) Grand average event-related potentials (ERPs)

\section{Summary}

To summarize, both emotion and neutral words elicited a significant post-N400 frontal positivity when emotionally unpredicted compared with when emotionally predicted. In addition, emotion words elicited reduced N400s when predicted compared with when unpredicted. With no emotional bias in the preceding context, emotion words elicited larger anterior P200 and LPC responses than did neutral words. Emotional contextual bias led to overall reduced N400s, and, critically, enhanced P200 and LPC emotion responses. The P200 context-driven emotion effect was observed only for neutral words, with neutral words eliciting enhanced anterior P200 responses statistically indistinguishable from the lexicaldriven P200 responses from emotion words in both contexts and were significantly larger than P200s from neutral words in a neutral context. Despite similar trends in the LPC contextdriven emotion effects, a modulation of word emotionality did not reach statistical significance. Finally, there was a significant correlation between empathy and lexical-driven LPC emotion responses from emotion words in the neutral context - with higher empathy associated with larger LPC responses. However, no significant correlations were obtained with empathy and other emotional responses.

\section{Discussion}

The present study explored the hypothesis that emotion processing in language involves not only the word that is being apprehended but also the context it is presented in. ERPs to

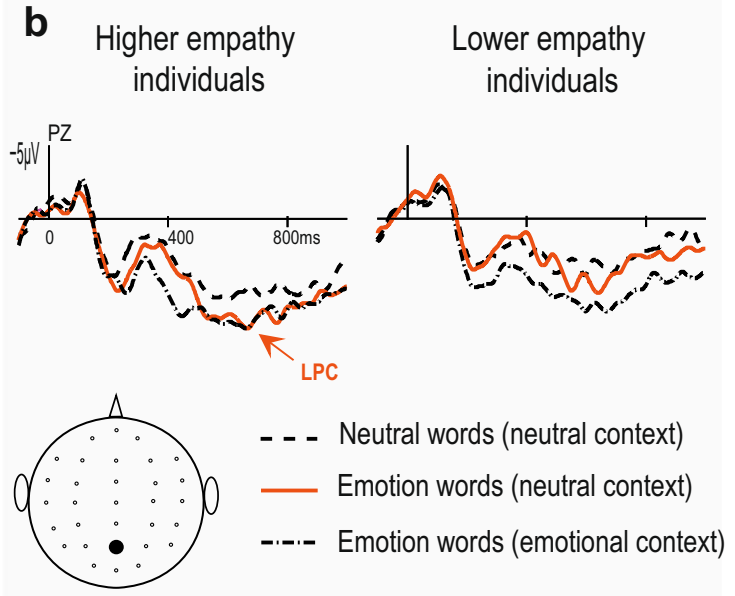

from a posterior representative electrode are plotted for emotion words in neutral sentences (orange solid line), overlaid with grand average ERPs for neutral words in neutral sentences (black dashed line) and emotion words in emotional sentences (black dash-dotted line) for comparisons 
coherent emotion and neutral words finishing sentences with or without strong constraint for the incoming valence were analyzed. We replicated emotion effects previously observed in the neutral context, with emotion words eliciting larger anterior P200 and LPC responses than did neutral words, demonstrating that word-level emotionality prompts immediate and robust attention allocation and further valence analysis. With emotional bias in the context, words elicited reduced N400 responses, indicating facilitated general semantic processing. Critically, we obtained evidence for contextualized emotion responses during coherent sentence comprehension. Our data demonstrated that, with contextually motivated active anticipation of the incoming emotionality (evidenced by the frontal positivity to emotionally unpredicted words), similar attention and evaluative processes could be triggered, seen in the form of enhanced P200 and LPC responses, respectively. Contextually driven emotion responses may sometimes even override the responses triggered by the word itself, leading to statistically equivalent $\mathrm{P} 200$ responses for emotion and neutral words in the emotional context. Intriguingly, although similar attention allocation and valence analysis could be initiated via word-level emotionality or context-level emotion constraints, they are not similarly accounted for by an individual's emotion empathy ability. While the lexical-driven LPC emotion responses were significantly correlated with empathy, contextual-driven LPC emotion responses were not, suggesting multiple routes for giving rise to these neurophysiological responses during emotion processing.

Together, our results provide support for contextualized emotion responses during comprehension of congruent sentences when a participant's active anticipation of the upcoming emotionality is promoted by the context. Our results also provide an initial understanding about how these emotion responses are mediated by empathy - an important aspect of human ability to perceive emotion. Below we discuss these points in turn.

\section{Active predictive emotion processing promoted by strong contextual valence constraint}

We found significant post-N400 frontal positivity effects to emotion and neutral words when they were emotionally unexpected, despite being coherent continuations in the given context. These results replicated prior findings of the frontal positivity when emotional sentence fragments were plausibly ended with valence-unexpected emotion words relative to valence-expected emotion words (e.g., expected/unexpected: "There was nothing special about the episode and it turned out to be very boring/interesting") (Moreno \& Rivera, 2014; Moreno \& Vázquez, 2011). As such, these results warrant the effectiveness of the manipulation on valence constraint in our materials and indicate that participants were in a state actively anticipating specific emotional valence when they read these sentences.

Similar frontal positivity has been seen when a strongly semantically constraining sentence like "His skin was red from spending the day at the....." did not continue with the expected word "beach," but instead with an unexpected plausible continuation like "farm" (Federmeier et al., 2007). This frontal positivity has been taken to reflect the consequences when a prediction is disconfirmed (Kutas, Federmeier, \& Urbach, 2014). The functional significance of the frontal positivity is still controversial (Federmeier, 2007; Kutas et al., 2014; Thornhill \& Van Petten, 2012). However, a recent time-frequency analysis discovered that frontal positivity shared similar resources with domaingeneral predictive mechanisms, suggesting that the frontal positivity effect may index a learning signal in response to prediction errors (Rommers, Dickson, Norton, Wlotko, \& Federmeier, 2017).

Prediction errors have been considered critical for learning, as they inform the system of the need to update and alter the current representations to form better predictions with less prediction errors in the long run. In light of this, the frontal positivity effect observed in the present study may reflect efforts to modify the valence concept associated with a lexical entry so as to render a more coherent emotion perception for this lexical item in the future. In that case, the frontal positivity effect observed here should be associated with subsequent changes in a word's perceived valence. This hypothesis needs to be confirmed in future investigations.

\section{Contextualized emotion responses to words during sentence comprehension}

Replicating prior research, our results showed that emotion words in a neutral context could trigger immediate and robust neurophysiological responses, indicating early attention allocation to emotion words (indexed by the P200 effect) and more controlled and continued deeper assessment of emotion due to its intrinsic motivational significance (indexed by the LPC effect) (Cuthbert, Schupp, Bradley, Birbaumer, \& Lang, 2000; Hajcak, MacNamara, \& Olvet, 2010; Hinojosa, Méndez-Bértolo, \& Pozo, 2010).

Critically, we also found modulations of valenceconstraining context, manifested by enhanced P200 and LPC responses to words in emotional context. These result patterns demonstrated that, like emotion words in a neutral context, emotion-constraining context could also induce emotion-related attention processes from the incoming word. Active anticipation of a certain emotion valence during reading, in particular, could similarly engage motivational circuits and heighten the attention resources, affecting early perception and subsequent affective evaluation of the incoming word, even when the word itself is emotionally neutral. These result patterns are in line with past research showing 
that behavioral ratings or affective brain responses to larger text passages can only be partially explained by valence values of the individual words that constitute the text (e.g., Hsu et al., 2015).

Interestingly, our results also indicate that contextualdriven emotion responses may sometimes override lexically driven emotion responses. When comparing responses in emotional context relative to neutral context, enhanced P200 responses were observed in neutral words only, leading to statistically indistinguishable P200 responses between emotion and neutral words in emotional context. These result patterns suggest that context-driven and stimulus-driven influences on early attention allocation to a word may not be additive and, when the contextual constraint is strong, the context may have the pivotal role of determining the emotional responses. These results do not suggest that contextual-driven influences would always override stimulus-driven ones, though. For linguistic contexts that are not as emotionally constraining as the ones used in the present study, the contextual-driven influences may interact with the stimulusdriven influences in other ways (e.g., Wang et al., 2013). Furthermore, as contextual integration relies on the ability to efficaciously make use of the linguistic context, influences from strongly constraining contexts could also be weaker for populations that are known to be less effective in making use of linguistic context. For example, it has been shown that while word-level stimulus-driven effects such as frequency effect tend to taper off toward the end of a sentence for young adults, it remains quite robust for older adults (Payne et al., 2015; Payne \& Federmeier, 2018).

The enhanced P200 and LPC responses to neutral words in emotional context implicate a possible mechanism for neutral words to pick up their emotional connotation senses through strongly constraining sentential context. Enhanced P200s to emotion words in neutral or isolated context have been thought to reflect the activation of subcortical pathways that are induced by repeated association between emotion and word form during the acquisition of a word's meaning (Kuchinke et al., 2014; LeDoux, 2000). It is possible that similar physiological responses induced by emotion context could also become part of the lexical representation after repeated association. This is not unlikely as novel word usage can be learned fairly easily in a strongly constraining context (Borovsky et al., 2010). Contextual learning of emotional connotations has also been demonstrated with nonverbal or meaningless neutral stimuli via evaluative conditioning paradigms. For example, emotionally conditioned pseudowords elicited larger positivity between 260 and $300 \mathrm{~ms}$ than did neutrally conditioned pseudowords (Fritsch \& Kuchinke, 2013); in addition, inherently neutral faces elicited enhanced LPC responses after being associated with positive monetary outcome (Hammerschmidt et al., 2018). In light of these observations, our results from neutral words in the emotional condition indicate that contextualized learning of emotion features may also occur for existing words within a sentence context.

Intriguingly, although similar attention allocation and valence analysis could be induced by word-level or context-level emotion features, our findings suggest the possibility of multiple routes that give rise to these neurophysiological responses. Extending prior research using non-verbal stimuli, our results indicate that more empathetic individuals are better able to perceive and appraise emotional content of emotion words in the sense that they are better able to initiate further evaluation on these stimuli. These results are in line with prior findings showing increased LPC emotion effect when the emotion is better "felt." For example, LPC amplitudes vary with the self-preferentiality of emotional stimuli, and are larger for words describing emotional experiences in reference to self than to other people (Herbert et al., 2011). Similarly, greater LPCs to emotion adjectives were found when participants thought that these were evaluative adjectives given by another human on their personality traits - when the evaluative adjectives were considered more self-relevant, as opposed to when participants thought these words were randomly generated by a computer (Schindler et al., 2014).

While the magnitude of lexically induced LPC emotion responses could be accounted for by an individual's emotion empathy, we did not find evidence for such a relation for other lexically driven or contextually driven emotion responses. These results are at odds with findings showing the role of empathy in recognizing emotion beyond the emotion features of the stimuli (Mayer et al., 1990), and suggest potential differences in contextualized emotion perception between language and non-verbal domains. It is possible that contextualized emotion responses rely more on linguistic capabilities to efficaciously making use of the context. It is also possible that empathy continues to play a role in contextualized emotion perception during comprehension, but its influence is harder to detect in the present study as the emotional constraint in the context provided strong facilitation for emotion perception, resulting in a limited range of variations in response. Future clarifications of these possibilties are needed.

\section{Facilitated semantic processing of words in an emotionally constraining context}

Finally, we discuss the constraint effect in the N400 components. While we did not find a significant effect of word emotionality, we observed a significant N400 difference to words following emotionally biased versus unbiased contexts, indicating an overall semantic-processing facilitation from the emotion constraint in the context. These results are broadly consistent with prior findings showing that emotional information has an influence on semantic association processes (Sass et al., 2012), and that emotional mood states could facilitate several different aspects of semantic processing (e.g., 
Federmeier et al., 2001; Hänze \& Hesse, 1993; Hanze \& Meyer, 1998).

Although the N400 constraint effect did not significantly interact with word emotionality, the effect was numerically larger for emotion words. Indeed, when tested as a function of emotion expectancy, the N400 difference between contexts was significant only for emotion words. These results are consistent with prior findings showing less negative N400s to emotionally congruent emotion words relative to emotionally incongruent emotion words (León et al., 2010; Moreno \& Rivera, 2014; Moreno \& Vázquez, 2011; Zhang et al., 2006). However, as all conditions in the present study were congruent and statistically matched for general expectedness, our findings help further extend this literature by demonstrating that these N400 differences may not simply reflect consequences of emotion or semantic violations or differences in general expectedness.

Taken at face value, the reduced N400s to emotion words in the emotional context in the present study appear to be in line with the recent discussions of the Affective Primacy Hypothesis (APH) in language comprehension. Recent findings showed that affective judgments were faster than nonaffective judgments on words appearing in an affective context (Lai et al., 2012), and that emotion words appearing in an emotional context elicited reduced N400 responses regardless of their valence congruency with the preceding context (Delaney-Busch \& Kuperberg, 2013). These results were interpreted as prioritized affective processing over semantic processing, in support of the APH (Zajonc, 2000).

However, other aspects of our results are harder to explain under these recent extensions of the APH. Within the general APH framework, Delaney-Busch and Kuperberg (2013) proposed a tradeoff between emotional salience and valence during the N400 time window that is contingent on the emotion constraint in the context. Specifically, for emotion words appearing in contexts highly constraining for emotional valence (like the ones used in the present study), valence would be prioritized over emotional salience during the N400 time window, leading to minimal subsequent LPC responses. Our results cannot be easily accounted for by this hypothesis as robust LPC responses were seen to emotion words relative to neutral words regardless of context.

In light of the current understanding of the functional significance of the frontal positivity that co-occurs with this N400 effect, an alternative explanation for the N400 reduction for emotion words in an emotionally biased context could be facilitated semantic processing due to preactivation of the relevant emotion attributes. Similar patterns of N400 reduction for unexpected but related endings have been found in the language-processing literature, thought to reflect a result of facilitation from preactivated semantic features. For example, N400s were reduced for the unexpected word "baseball" relative to another equally unexpected word "monopoly" in the sentence
"He caught the pass and scored another touch-down. There was nothing he enjoyed more than a good game of baseball/monopoly." This was considered to reflect processing facilitation for the unexpected word "baseball" because of the pre-activated ball-game-related semantic features shared between the expected word "football" and the actually apprehended word "baseball" (Federmeier \& Kutas, 1999; Marta Kutas \& Hillyard, 1984; also see Federmeier, 2007, for a review). Our stimuli are similar to the above example in the following sense: In our study, emotionally predicted emotion words were lexically unexpected in the given sentence frames as we wanted to match the cloze probabilities between emotionally predicted and unpredicted words; nevertheless, emotionally predicted emotion words by definition shared the valence with the originally expected lexical item. As such, processing of the target emotion words could be facilitated due to pre-activated features pertaining to the expected valence, leading to the N400 reduction. Similar valencecongruent priming has been shown with non-verbal materials (e.g., Hansen \& Shantz, 1995; Hietanen \& Astikainen, 2013).

Prior studies have demonstrated pre-activation of several types of linguistic features, including orthographic, semantic, phonological, and syntactic features during comprehension of highly constraining sentences (see Kutas et al., 2014, for a review). If the above interpretation holds, our results would add to this literature by showing that emotion-related attributes could also be pre-activated when the context forms a strong constraint for the subsequent valence.

\section{Conclusion}

Our study demonstrated that emotion processing during language comprehension is jointly affected by emotion concepts linked to the lexical items and derived from the context. Our results highlight the constitutive role of language in more general human emotion processes, shaping emotion responses even when an explicit emotion evaluation of the materials was not required. Moreover, our results endorse the potential of emotion in sculpting language representations (Hinojosa et al., 2019; van Berkum, 2018). With duality of patterning, human language representations are highly malleable and statistical in the face of new evidence (Fine \& Jaeger, 2013; Norris et al., 2003; Ryskin et al., 2017), among which a crucial influence could be emotion.

Open Practices Statement The datasets generated and/or analyzed during the current study are available from the corresponding author on reasonable request. 
Acknowledgements The authors wish to thank Wei-Hong Lin for preparation of the tables. This study was supported by a Ministry of Science and Technology grant (MOST 108-2410-H-002 -056 -MY2) to Chia-lin Lee.

\section{References}

Barrett, L. F., Lindquist, K. A., \& Gendron, M. (2007). Language as context for the perception of emotion. Trends in Cognitive Sciences, 11(8), 327-332. https://doi.org/10.1016/j.tics.2007.06. 003

Bayer, M., Sommer, W., \& Schacht, A. (2010). Reading emotional words within sentences: The impact of arousal and valence on eventrelated potentials. International Journal of Psychophysiology: Official Journal of the International Organization of Psychophysiology, 78(3), 299-307. https://doi.org/10.1016/j. ijpsycho.2010.09.004

Borovsky, A., Kutas, M., \& Elman, J. (2010). Learning to use words: Event related potentials index single-shot contextual word learning. Cognition, 116(2), 289-296. https://doi.org/10.1016/j.cognition. 2010.05.004

Chan, J. C. (1986). Nianji, xingbei juese, renqing quxiang yu tonglixin de guanxi [The relationship between grade, gender roles, relationshiporiented and empathy](Master's thesis, National Chengchi University, Taipei, Taiwan). Retrieved from http:// nccur.lib.nccu.edu.tw/handle/140.119/48390

Citron, F. M. M. (2012). Neural correlates of written emotion word processing: A review of recent electrophysiological and hemodynamic neuroimaging studies. Brain and Language, 122(3), 211-226. https://doi.org/10.1016/j.bandl.2011.12.007

Cuthbert, B. N., Schupp, H. T., Bradley, M. M., Birbaumer, N., \& Lang, P. J. (2000). Brain potentials in affective picture processing: covariation with autonomic arousal and affective report. Biological Psychology, 52(2), 95-111.

Delaney-Busch, N., \& Kuperberg, G. (2013). Friendly drug-dealers and terrifying puppies: Affective primacy can attenuate the N400 effect in emotional discourse contexts. Cognitive, Affective \& Behavioral Neuroscience, 13(3), 473-490. https://doi.org/10.3758/s13415-013$0159-5$

Delorme, A. and Makeig, S. (2004) EEGLAB: an open sorce toolbox for analysis of single-trail EEG dynamics including independent component anlaysis. Journal of Neuroscience Methods, 134, 9-21.

Dimberg, U., Andréasson, P., \& Thunberg, M. (2011). Emotional empathy and facial reactions to facial expressions. Journal of Psychophysiology, 25(1), 26-31. https://doi.org/10.1027/02698803/a000029

Ding, J., Wang, L., \& Yang, Y. (2015). The dynamic influence of emotional words on sentence processing. Cognitive, Affective \& Behavioral Neuroscience, 15(1), 55-68. https://doi.org/10.3758/ s13415-014-0315-6

Ding, J., Wang, L., \& Yang, Y. (2016). The dynamic influence of emotional words on sentence comprehension: An ERP study. Cognitive, Affective, \& Behavioral Neuroscience, 16(3), 433-446. https://doi. org/10.3758/s13415-016-0403-x

Espuny, J., Jiménez-Ortega, L., Casado, P., Fondevila, S., Muñoz, F., Hernández-Gutiérrez, D., \& Martín-Loeches, M. (2018). Eventrelated brain potential correlates of words' emotional valence irrespective of arousal and type of task. Neuroscience letters, 670, 8388.

Federmeier, K. D., \& Kutas, M. (1999). A rose by any other name: Longterm memory structure and sentence processing. Journal of Memory and Language, 41(4), 469-495.

Federmeier, K. D., Kirson, D. A., Moreno, E. M., \& Kutas, M. (2001). Effects of transient, mild mood states on semantic memory organization and use: an event-related potential investigation in humans. Neuroscience Letters, 305(3), 149-152.

Federmeier, K.D., 2007. Thinking ahead: the role and roots of prediction in language comprehension. Psychophysiology 44 (4), 491-505.

Federmeier, K. D., Wlotko, E. W., De Ochoa-Dewald, E., \& Kutas, M. (2007). Multiple effects of sentential constraint on word processing. Brain Research, 1146, 75-84. https://doi.org/10.1016/j.brainres. 2006.06.101

Fields, E. C., \& Kuperberg, G. R. (2012). It's All About You: An ERP Study of Emotion and Self-Relevance in Discourse. NeuroImage, 62(1), 562-574. https://doi.org/10.1016/j.neuroimage.2012.05.003

Fine, A. B., \& Jaeger, F. T. (2013). Evidence for Implicit Learning in Syntactic Comprehension. Cognitive Science, 37(3), 578-591. https://doi.org/10.1111/cogs.12022

Fritsch, N., \& Kuchinke, L. (2013). Acquired affective associations induce emotion effects in word recognition: An ERP study. Brain and Language, 124(1), 75-83. https://doi.org/10.1016/j.bandl.2012.12. 001

Gole, M., Schäfer, A., \& Schienle, A. (2012). Event-related potentials during exposure to aversion and its anticipation: The moderating effect of intolerance of uncertainty. Neuroscience Letters, 507(2), 112-117. https://doi.org/10.1016/j.neulet.2011.11.054

Hajcak, G., MacNamara, A., \& Olvet, D. M. (2010). Event-related potentials, emotion, and emotion regulation: an integrative review. Developmental Neuropsychology, 35(2), 129-155.

Halberstadt, J. B., \& Niedenthal, P. M. (2001). Effects of emotion concepts on perceptual memory for emotional expressions. Journal of Personality and Social Psychology, 81(4), 587-598.

Hammerschmidt, W., Kagan, I., Kulke, L., \& Schacht, A. (2018). Implicit reward associations impact face processing: Time-resolved evidence from event-related brain potentials and pupil dilations. NeuroImage, 179, 557-569. https://doi.org/10.1016/j.neuroimage.2018.06.055

Hansen, C. H., \& Shantz, C. A. (1995). Emotion-Specific Priming: Congruence Effects on Affect and Recognition Across Negative Emotions. Personality and Social Psychology Bulletin, 21(6), 548-557. https://doi.org/10.1177/0146167295216001

Hänze, M., \& Hesse, F. W. (1993). Emotional influences on semantic priming. Cognition and Emotion, 7(2), 195-205. https://doi.org/10. 1080/02699939308409184

Hanze, M., \& Meyer, H. A. (1998). Mood influences on automatic and controlled semantic priming. The American Journal of Psychology; Urbana, 111(2), 265-278. https://doi.org/10.2307/1423489

Herbert, C., Herbert, B. M., Ethofer, T., \& Pauli, P. (2011). His or mine? The time course of self-other discrimination in emotion processing. Social Neuroscience, 6(3), 277-288. https://doi.org/10.1080/ 17470919.2010 .523543

Herbert, C., Junghofer, M., \& Kissler, J. (2008). Event related potentials to emotional adjectives during reading. Psychophysiology, 45(3), 487-498. https://doi.org/10.1111/j.1469-8986.2007.00638.x

Hietanen, J. K., \& Astikainen, P. (2013). N170 response to facial expressions is modulated by the affective congruency between the emotional expression and preceding affective picture. Biological Psychology, 92(2), 114-124. https://doi.org/10.1016/j.biopsycho. 2012.10.005

Hinojosa, J. A., Méndez-Bértolo, C., \& Pozo, M. A. (2010). Looking at emotional words is not the same as reading emotional words: Behavioral and neural correlates. Psychophysiology, 47(4), 748757.

Hinojosa, J. A., Méndez-Bértolo, C., \& Pozo, M. A. (2012). High arousal words influence subsequent processing of neutral information: Evidence from event-related potentials. International Journal of Psychophysiology, 86(2), 143-151. https://doi.org/10.1016/j. ijpsycho.2012.06.001

Hinojosa, J. A., Moreno, E. M., \& Ferré, P. (2019). Affective neurolinguistics: towards a framework for reconciling language and emotion. Language, Cognition and Neuroscience, 1-27. 
Holt, D. J., Lynn, S. K., \& Kuperberg, G. R. (2009). Neurophysiological Correlates of Comprehending Emotional Meaning in Context. Journal of Cognitive Neuroscience, 21(11), 2245-2262. https:// doi.org/10.1162/jocn.2008.21151

Hsu, C. T., Jacobs, A. M., Citron, F. M., \& Conrad, M. (2015). The emotion potential of words and passages in reading Harry PotterAn fMRI study. Brain and language, 142, 96-114.

Jiménez-Ortega, L., Martín-Loeches, M., Casado, P., Sel, A., Fondevila, S., de Tejada, P. H., ... Sommer, W. (2012). How the Emotional Content of Discourse Affects Language Comprehension. PLOS ONE, 7(3), e33718. https://doi.org/10.1371/journal.pone.0033718

Kanske, P., \& Kotz, S. A. (2007). Concreteness in emotional words: ERP evidence from a hemifield study. Brain Research, 1148, 138-148. https://doi.org/10.1016/j.brainres.2007.02.044

Kissler, J., Herbert, C., Winkler, I., \& Junghofer, M. (2009). Emotion and attention in visual word processing-An ERP study. Biological Psychology, 80(1), 75-83. https://doi.org/10.1016/j.biopsycho. 2008.03.004

Kotz, S. A., \& Paulmann, S. (2011). Emotion, Language, and the Brain. Language and Linguistics Compass, 5(3), 108-125. https://doi.org/ 10.1111/j.1749-818X.2010.00267.x

Kuchinke, L., Krause, B., Fritsch, N., \& Briesemeister, B. B. (2014). A familiar font drives early emotional effects in word recognition. Brain and Language, 137, 142-147. https://doi.org/10.1016/j. bandl.2014.08.007

Kutas, M., \& Hillyard, S. A. (1984). Brain potentials during reading reflect word expectancy and semantic association. Nature, 307(5947), 161-163.

Kutas, M., \& Federmeier, K. D. (2011). Thirty Years and Counting: Finding Meaning in the N400 Component of the Event-Related Brain Potential (ERP). Annual Review of Psychology, 62, 621647. https://doi.org/10.1146/annurev.psych.093008.131123

Kutas, M., Federmeier, K. D., \& Urbach, T. (2014). The "negatives" and "positives" of prediction in language. In M. S. Gazzaniga (Ed.), The Cognitive Neurosciences (5th Edition). (pp. 649-656). Cambridge: MIT Press.

Lai, V. T., Hagoort, P., \& Casasanto, D. (2012). Affective Primacy vs. Cognitive Primacy: Dissolving the Debate. Frontiers in Psychology, 3. https://doi.org/10.3389/fpsyg.2012.00243

LeDoux, J. E. (2000). Emotion circuits in the brain. Annual Review of Neuroscience, 23, 155-184. https://doi.org/10.1146/annurev.neuro. 23.1.155

Lee, Y., Yang, M. J., Lai, T. J., Chiu, N. M., \& Chau, T. T. (2000). Development of the Taiwanese Depression Questionnaire. Chang Gung Medical Journal, 23(11), 688-694.

León, I., Díaz, J. M., de Vega, M., \& Hernández, J. A. (2010). Discoursebased emotional consistency modulates early and middle components of event-related potentials. Emotion (Washington, D.C.), 10(6), 863-873. https://doi.org/10.1037/a0019983

Li, Y., \& Yu, D. (2015). Development of emotion word comprehension in Chinese children from 2 to 13 years old: Relationships with valence and empathy. PloS one, 10(12), e0143712.

Lin, H., Gao, H., Ye, Z., Wang, P., Tao, L., Ke, X., ... Jin, H. (2012). Expectation enhances event-related responses to affective stimuli. Neuroscience Letters, 522(2), 123-127. https://doi.org/10.1016/j. neulet.2012.06.022

Lindquist, K. A., \& Barrett, L. F. (2008). Constructing emotion: The experience of fear as a conceptual act. Psychological Science, 19(9), 898-903. https://doi.org/10.1111/j.1467-9280.2008.02174.x

Lindquist, K. A., Satpute, A. B., \& Gendron, M. (2015). Does Language Do More Than Communicate Emotion? Current Directions in Psychological Science, 24(2), 99-108. https://doi.org/10.1177/ 0963721414553440

Lopez-Calderon, J. and Luck, S.J. (2014) ERPLAB: an open-source toolbox for the analysis of event-related potentials. Frontiers in Human Neuroscience 8(April), 1-14.
Martín-Loeches, M., Fernández, A., Schacht, A., Sommer, W., Casado, P., Jiménez-Ortega, L., \& Fondevila, S. (2012). The influence of emotional words on sentence processing: Electrophysiological and behavioral evidence. Neuropsychologia, 50(14), 3262-3272. https://doi.org/10.1016/j.neuropsychologia.2012.09.010

Mayer, J. D., DiPaolo, M., \& Salovey, P. (1990). Perceiving Affective Content in Ambiguous Visual Stimuli: A Component of Emotional Intelligence. Journal of Personality Assessment, 54(3-4), 772-781. https://doi.org/10.1080/00223891.1990.9674037

Mehrabian, A., \& Epstein, N. (1972). A measure of emotional empathy. Journal of Personality, 40(4), 525-543. https://doi.org/10.1111/j. 1467-6494.1972.tb00078.x

Mehrabian, A., Young, A. L., \& Sato, S. (1988). Emotional empathy and associated individual differences. Current Psychology, 7(3), 221240. https://doi.org/10.1007/BF02686670

Moreno, E. M., \& Rivera, I. C. (2014). Setbacks, pleasant surprises and the simply unexpected: Brainwave responses in a language comprehension task. Social Cognitive and Affective Neuroscience, 9(7), 991-999. https://doi.org/10.1093/scan/nst066

Moreno, E. M., \& Vázquez, C. (2011). Will the glass be half full or half empty? Brain potentials and emotional expectations. Biological Psychology, 88(1), 131-140. https://doi.org/10.1016/j.biopsycho. 2011.07.003

Norris, D., McQueen, J. M., \& Cutler, A. (2003). Perceptual learning in speech. Cognitive Psychology, 47(2), 204-238.

Oldfield, R. C. (1971). The assessment and analysis of handedness: The Edinburgh inventory. Neuropsychologia, 9, 97-113.

Payne, B. R., \& Federmeier, K. D. (2018). Contextual constraints on lexico-semantic processing in aging: Evidence from single-word event-related brain potentials. Brain Research, 1687, 117-128. https://doi.org/10.1016/j.brainres.2018.02.021

Payne, B. R., Lee, C.-L., \& Federmeier, K. D. (2015). Revisiting the incremental effects of context on word processing: Evidence from single-word event-related brain potentials. Psychophysiology, 52(11), 1456-1469. https://doi.org/10.1111/psyp.12515

Rommers, J., Dickson, D. S., Norton, J. J., Wlotko, E. W., \& Federmeier, K. D. (2017). Alpha and theta band dynamics related to sentential constraint and word expectancy. Language, Cognition and Neuroscience, 32(5), 576-589.

Ryskin, R., Ng, S., Mimnaugh, K., Brown-Schmidt, S., \& Federmeier, K. D. (2020). Talker-specific predictions during language processing. Language, Cognition and Neuroscience, 35(6), 797-812.

Ryskin, R. A., Qi, Z., Duff, M. C., \& Brown-Schmidt, S. (2017). Verb Biases Are Shaped Through Lifelong Learning. Journal of Experimental Psychology, 43(5), 781-794. https://doi.org/10.1037/ $\mathrm{x} \operatorname{lm} 0000341$

Sass, K., Habel, U., Sachs, O., Huber, W., Gauggel, S., \& Kircher, T. (2012). The influence of emotional associations on the neural correlates of semantic priming. Human Brain Mapping, 33(3), 676694. https://doi.org/10.1002/hbm.21241

Schindler, S., Wegrzyn, M., Steppacher, I., \& Kissler, J. (2014). It's all in your head - how anticipating evaluation affects the processing of emotional trait adjectives. Frontiers in Psychology, 5. ://doi.org/10. 3389/fpsyg.2014.01292

Sonnby-Borgström, M. (2002). Automatic mimicry reactions as related to differences in emotional empathy. Scandinavian Journal of Psychology, 43(5), 433-443.

Stanovich, K. E., \& West, R. F. (1989). Exposure to Print and Orthographic Processing. Reading Research Quarterly, 24(4), 402-433. https://doi.org/10.2307/747605

Taylor, W. L. (1953). "Cloze Procedure": A New Tool for Measuring Readability. Journalism Bulletin, 30(4), 415-433. https://doi.org/ 10.1177/107769905303000401

Thornhill, D. E., \& Van Petten, C. (2012). Lexical versus conceptual anticipation during sentence processing: Frontal positivity and 
N400 ERP components. International Journal of Psychophysiology, 83(3), 382-392.

Van Petten, C., Luka, B.J. (2012). Prediction during language comprehension: Benefits, costs, and ERP components. International Journal of Psychophysiology, 83(2), 176-90.

van Berkum, J. J. A. (2018). Language comprehension, emotion, and sociality: Aren't we missing something? [Part of book]. Retrieved August 20, 2019, from http://dspace.library.uu.nl/handle/1874/ 370175

Van den Brink, D., Van Berkum, J. J., Bastiaansen, M. C., Tesink, C. M., Kos, M., Buitelaar, J. K., \& Hagoort, P. (2012). Empathy matters: ERP evidence for inter-individual differences in social language processing. Social cognitive and affective neuroscience, 7(2), 173183.

Wang, L., \& Bastiaansen, M. (2014). Oscillatory brain dynamics associated with the automatic processing of emotion in words. Brain and Language, 137, 120-129. https://doi.org/10.1016/j.band1.2014.07. 011
Wang, L., Bastiaansen, M., Yang, Y., \& Hagoort, P. (2013). ERP evidence on the interaction between information structure and emotional salience of words. Cognitive, Affective \& Behavioral Neuroscience, 13(2), 297-310. https://doi.org/10.3758/s13415012-0146-2

Zajonc, R. B. (2000). Feeling and thinking: Closing the debate over the independence of affect. In Studies in Emotion and Social Interaction, Second Series. Feeling and thinking: The role of affect in social cognition (pp. 31-58). New York, NY, US: Cambridge University Press.

Zhang, Q., Lawson, A., Guo, C., \& Jiang, Y. (2006). Electrophysiological correlates of visual affective priming. Brain Research Bulletin, 71(1), 316-323. https://doi.org/10.1016/j.brainresbull.2006.09.023

Publisher's note Springer Nature remains neutral with regard to jurisdictional claims in published maps and institutional affiliations. 